\title{
Early Initiation of Antenatal Care and Factors Associated with Early Antenatal Care Initiation at Health Facilities in Southern Ethiopia
}

\author{
Mengesha Boko Geta ${ }^{1}$ and Walelegn Worku Yallew ${ }^{2}$ \\ ${ }^{1}$ Kebado Primary Hospital, Hawassa, Ethiopia \\ ${ }^{2}$ Institute of Public Health, College of Medicine and Health Sciences, University of Gondar, Gondar, Ethiopia \\ Correspondence should be addressed to Mengesha Boko Geta; mengeshaokkob@yahoo.com
}

Received 10 February 2017; Revised 21 June 2017; Accepted 30 July 2017; Published 18 September 2017

Academic Editor: Jennifer L. Freeman

Copyright (c) 2017 Mengesha Boko Geta and Walelegn Worku Yallew. This is an open access article distributed under the Creative Commons Attribution License, which permits unrestricted use, distribution, and reproduction in any medium, provided the original work is properly cited.

\begin{abstract}
Antenatal care (ANC) is care given to pregnant mothers to timely identify and mitigate pregnancy related problems that can harm mother or fetus. Most of Ethiopian mothers present late for ANC. The aim of this paper was to assess determinants of early antenatal care initiation among pregnant women. Mothers attending Shebedino District Health Centers for ANC between January 12 and February 18, 2015, were invited to the study. Multistage sampling technique and structured questionnaire were used to collect data by trained data collectors. Univariate and bivariate analysis were conducted to study the association between explanatory and outcome variable. Out of 608 women, 132 [21.71\%] had their first ANC within the recommended time [before or at 3 months]. Media access $[\mathrm{AOR}=2.1195 \% \mathrm{CI} 1.00,3.22]$, knowledge about the correct time of ANC booking [AOR $=4.4995 \%$ CI 2.47, 6.16], and having been advised to book within 12 weeks [AOR $=4.1495 \%$ CI 3.80, 5.21] were determinants of first-trimester booking. Health professionals and care providers should provide full information, advice, and appropriate care about early ANC for every eligible mother.
\end{abstract}

\section{Introduction}

The care that was given to the mother during pregnancy, during delivery, and after delivery is important for the wellbeing of the mother and the child. All pregnant ladies are recommended to go for their first antenatal check-up in the first trimester to identify and manage any medical complication as well as to screen them for any risk factors that may affect the progress and outcome of their pregnancy [1]. The first visit which is expected to screen and treat anemia and syphilis, screen for risk factors and medical conditions that can be best dealt with in early pregnancy, and initiate prophylaxis if required (e.g., for anemia and malaria) is recommended to be held by the end of fourth month [2]. ANC helps to ensure the well-being of the mother and fetus through early detection of risks in pregnancy, prevention of pregnancy, and labor complications and ensures the safe delivery of mother and child [3]. In Ethiopia, 34\% of pregnant women attend antenatal care at least once and 19\% of them attend four times and only $11.2 \%$ attend early [4]. In Ethiopia, antennal care services increased in the past 15 years from 27 percent in 2000 to 62 percent in 2015. However, it needs further improvement to achieve [5-7].

Globally, approximately 515,000 women die from pregnancy related complications each year [8]. In developing world over 30 million women suffer each year from serious obstetric complications [9]. Inadequate access and underutilization of modern healthcare services are major reasons for poor health in the developing countries. This inequality in the health and well-being of women in the developing world is a growing concern [10]. Although services are given freely, a number of factors have been found to contribute to late initiation of ANC among pregnant women and these may vary between rural and urban areas [11].

Pregnant women should be offered screening for HIV infection early in ANC [12]. Low ANC coverage, few visits, and late attendance at first antenatal visit are common 
problems throughout Sub-Saharan Africa posing difficulty in accomplishing the WHO recommended ANC schedule [13].

Late ANC initiation may increase the total cost of caring for a pregnant woman [14]. A study conducted in Hadiya zone Southern Ethiopia revealed that, concerning time of initiating care, only $8.7 \%$ of the ANC attendants initiated care during the first trimester of pregnancy while $68.1 \%$ had the first visit during the third trimester [15]. Another study in Ethiopia showed that proper advice and information on timely booking from service providers and community level are very important for the effective utilization of the service [16].

Women in developing countries, particularly in SubSaharan Africa, tend to wait to start antenatal care until the second or third trimester [17]. The standard of care when evaluating a woman with a potentially complicated firsttrimester pregnancy is to take a detailed history of the risk factors and ascertain the clinical course [18]. Educational status of the women and family income were independent factors for late initiation of ANC [19]. Pregnant mothers at younger age [20] register early for ANC compared to older age and younger women are more likely to accept modern health care as they are likely to have greater experience to modern medicine [21].

Women who have lower educational status, have good perception, and are urban residents are more likely to attend early for ANC compared to their counterparts [10,22]. Parity [22] and late ANC initiation are also a factor for ANC utilization [23]. The aim of this study is to assess the magnitude and factors associated with early antenatal care initiation of mothers in health facilities.

\section{Materials and Methods}

Study was conducted in Shebedino district, which is one of 19 rural woredas of Sidama zone in Southern regions of Ethiopia, which is located $28 \mathrm{KM}$ from capital city of southern regions, Hawassa, and organised by 32 rural and 3 urban kebeles for the purpose of administration. Source population was all mothers attending Shebedino district health facilities in Sidama zone. The study population was pregnant mothers attending Shebedino district health facilities for ANC services during study period with inclusion criteria of pregnant mothers attending those health facilities during study period for ANC services and exclusion criteria of pregnant mothers with some serious illness and labor. Five health centers were randomly selected by lottery method among 9 health centers in the woreda and 1 primary hospital. Multistage sampling technique was applied till the sample size was enough. Sample proportion or number of eligible pregnant mothers was calculated based on catchment population proportion using exit interview at every third mother.

The sample size was calculated using single population proportion based on the study conducted on timing of first ANC visit at Gondar Hospital, and a prevalence of $47.2 \%$ was taken to estimate the sample size [20]. Six hundred thirty mothers were included in the study with an assumption of $95 \%$ confidence interval, $5 \%$ margin of error, $10 \%$ nonresponse rate, and a design effect of 1.5 .
A pretested questionnaire which consists of a sociodemographic characteristic, obstetric information, and decisionmaking status of women was used. The data collection was exit interview with pregnant mothers after service of ANC Department of Health Facilities. The data was collected by trained clinical nurses or midwifes who were selected from other catchments which are not selected for data collection. Data collectors were supervised by trained supervisors daily during data collection. Before data collection, ethical approval was taken from IRB of Addis Continental Institute of Public Health and informed consent and confidentiality were assured by data collectors to the participants.

Questionnaire was checked daily by the principal investigator for consistency. The selecting criteria of data collectors were ability to speak local language, interest to participate, and being well mannered and disciplined. Data was entered into EPI info version 3.5.1 and transferred to Statistical Package for Social Science (SPSS) version 20.0 software for analysis. Descriptive and summary statistics was carried out. $P$ value 0.05 was considered statistical significance. Bivariate and multivariate logistic regression analyses were used to identify variables associated with early antenatal initiation.

\section{Result}

Out of 631 pregnant women who initiated to be included in this study, 608 [96.3\%] have responded to the interview. The remaining 17 [2.7\%] did not respond to the interview while 6 [1\%] of them were unable to respond or they did not specify the gestational age when they started the ANC. The median age of respondents was 25 years ranging from 15 to 40 years (Table 1).

3.1. Obstetric History and Timing of First ANC Visits. Majority, 409 [67.3\%], of respondents had parity one and above, while 184 [30.3\%] have no parity and the remaining 15 [2.4\%] of the respondents had history of parity greater than five (Table 2).

\subsection{Knowledge and Perception of ANC Service Utilization and} First Timing of ANC Visit. Majority, 596 [98.2\%], of respondents perceived and rated that the importance of ANC for the health of the mother and fetus was highly important to the health of mother and fetus. Two-thirds, 410 [67.4\%], of the respondents perceived that the correct time of ANC starting was after 12 weeks of gestation followed by 169 [27.8\%] who perceived that the correct time of ANC starting was before 12 weeks of gestation. 26 [4.3\%] respondents perceived that only one visit of ANC was enough, 76 [12.5\%] perceived that two to three visits of ANC were necessary, 430 [70.8\%] perceived that four to six visits of ANC were necessary, and 75 [12.4\%] perceived that more than six ANC visits are necessary (Table 3).

3.3. Factors Associated with Timely ANC Initiation. Bivariate analysis showed that respondents who had media access $(\mathrm{TV} /$ radio $)[\mathrm{OR}=1.48595 \%$ CI $1.002,2.202]$, who had perceived that the correct time of ANC booking is within 12 weeks of gestation [OR $=20.75595 \%$ CI 12.816, 33.613], 
TABLE 1: Sociodemographic characteristics of respondents by time of ANC booking in Shebedino district in 2015.

\begin{tabular}{|c|c|c|c|}
\hline Variable & Description & Frequency & Percentage \\
\hline \multirow{6}{*}{ Age in years: $n=608$} & $15-19$ & 66 & $10.8 \%$ \\
\hline & $20-24$ & 247 & $40.6 \%$ \\
\hline & $25-29$ & 195 & $32.0 \%$ \\
\hline & $30-34$ & 65 & $10.7 \%$ \\
\hline & $35-39$ & 28 & $4.6 \%$ \\
\hline & $40-45$ & 7 & $1.1 \%$ \\
\hline \multirow{5}{*}{ Ethnicity: $n=608$} & Sidama & 548 & $90.1 \%$ \\
\hline & Amahara & 23 & $3.8 \%$ \\
\hline & Guragie & 18 & $2.9 \%$ \\
\hline & Silte & 5 & $0.8 \%$ \\
\hline & Wolaita & 14 & $2.3 \%$ \\
\hline \multirow{4}{*}{ Religion: $n=608$} & Orthodox & 37 & $6.0 \%$ \\
\hline & Muslim & 43 & $7.0 \%$ \\
\hline & Protestant & 510 & $83.8 \%$ \\
\hline & Catholic & 18 & $2.9 \%$ \\
\hline \multirow{4}{*}{ Marital status: $n=608$} & Single [not married] & 7 & $1.1 \%$ \\
\hline & Married and live together & 594 & $97.6 \%$ \\
\hline & Cohabitation & 5 & $0.8 \%$ \\
\hline & Ever married but separated & 2 & $0.3 \%$ \\
\hline \multirow{5}{*}{ Educational level [completed]: $n=608$} & Illiterate [cannot read \& write] & 155 & $25.5 \%$ \\
\hline & Illiterate [can read and write] & 23 & $3.7 \%$ \\
\hline & Primary $[1-8]$ & 333 & $54.7 \%$ \\
\hline & Secondary $[9-12]$ & 63 & $10.7 \%$ \\
\hline & Diploma and above & 34 & $5.6 \%$ \\
\hline \multirow{2}{*}{ Residence: $n=608$} & Urban & 63 & $10.36 \%$ \\
\hline & Rural & 545 & $89.64 \%$ \\
\hline \multirow{3}{*}{ Income per month: $n=608$} & $<400.00 \mathrm{ETB}$ & 275 & $45.23 \%$ \\
\hline & $400.00-1000.00 \mathrm{ETB}$ & 235 & $38.65 \%$ \\
\hline & $>1000.00 \mathrm{ETB}$ & 98 & $16.12 \%$ \\
\hline \multirow{4}{*}{$\begin{array}{l}\text { Media access (source of information) } \\
n=608\end{array}$} & Television & 89 & $14.63 \%$ \\
\hline & Radio & 192 & $31.57 \%$ \\
\hline & Village & 284 & $46.70 \%$ \\
\hline & None & 43 & $7.07 \%$ \\
\hline
\end{tabular}

TABLE 2: Number of respondents by obstetric history and time of first ANC, Shebedino district in 2015.

\begin{tabular}{|c|c|c|c|}
\hline Variable & Description & Frequency & Percentage \\
\hline \multirow{3}{*}{ Parity $n=608$} & No parity & 184 & $30.26 \%$ \\
\hline & Parity $1-5$ & 409 & $67.26 \%$ \\
\hline & Parity $>5$ & 15 & $12.46 \%$ \\
\hline \multirow{2}{*}{ Gravidity $n=608$} & No gravidity & 170 & $27.96 \%$ \\
\hline & One and above & 438 & $72.04 \%$ \\
\hline \multirow{2}{*}{ Abortion $n=608$} & Had no history of abortion & 554 & $91.11 \%$ \\
\hline & Had history of abortion & 54 & $8.89 \%$ \\
\hline \multirow{2}{*}{ Types of abortion $n=54$} & Had at least one spontaneous abortion & 45 & $83.33 \%$ \\
\hline & Had at least one induced abortion & 9 & $16.67 \%$ \\
\hline \multirow{2}{*}{$\begin{array}{l}\text { History of child death } \\
n=608\end{array}$} & Had history of child death & 28 & $4.60 \%$ \\
\hline & Had no history of child death & 580 & $95.40 \%$ \\
\hline
\end{tabular}

who booked first ANC within the recommended time for the past pregnancy preceding the current $[\mathrm{OR}=20.51295 \%$ CI 12.671, 33.206], who received advise on early booking [OR $=17.88595 \%$ CI 11.218, 28.513], who ever use ANC before current pregnancy [OR $=5.0495 \%$ CI 2.85, 8.91], and who were prim gravid $[\mathrm{OR}=1,65895 \%$ CI 1.100, 2.498] were positively associated and more likely to book first ANC within recommended time compared to their counterparts (Table 4).

Multivariate analysis showed that respondents with media access (who had TV/radio) [OR $=2.109$ 95\% CI 1.001, 4.445], who perceived that the correct time of ANC booking is within 12 weeks of gestation [OR $=4.499$ 95\% CI 4.470 , 16.160], and who received advise on booking time within 12 
TABLE 3: Knowledge and perception of ANC service utilization and timing of first ANC, Shebedino in district SNNPR, Ethiopia, in 2015.

\begin{tabular}{|c|c|c|c|}
\hline Variable & Description & Frequency & Percentage \\
\hline \multirow{3}{*}{$\begin{array}{l}\text { Perception of importance of ANC for } \\
\text { health of mother } n=607\end{array}$} & Highly important & 596 & $98.18 \%$ \\
\hline & Medium importance & 4 & $0.65 \%$ \\
\hline & Less important & 7 & $1.15 \%$ \\
\hline \multirow{3}{*}{$\begin{array}{l}\text { Perception of importance of care for the } \\
\text { health of the fetus: } n=608\end{array}$} & Highly important & 598 & $98.35 \%$ \\
\hline & Medium importance & 2 & $0.32 \%$ \\
\hline & Less important & 8 & $1.32 \%$ \\
\hline \multirow{2}{*}{$\begin{array}{l}\text { Perceptions on timing of first care: } \\
n=608\end{array}$} & Before and at 12 weeks of gestation & 169 & $27.79 \%$ \\
\hline & After 12 weeks of gestation & 430 & $72.20 \%$ \\
\hline \multirow{4}{*}{$\begin{array}{l}\text { Perceived number of ANC visits of } \\
\text { pervious pregnancy } n=607\end{array}$} & Only one ANC visit enough & 27 & $4.44 \%$ \\
\hline & 2-3 ANC visits enough & 76 & $12.52 \%$ \\
\hline & 4-6 ANC visits enough & 430 & $70.84 \%$ \\
\hline & $>6$ ANC visits enough & 75 & $12.35 \%$ \\
\hline \multirow{2}{*}{$\begin{array}{l}\text { Early antenatal booking is good for } \\
\text { pregnancy of mother } n=608\end{array}$} & I agree & 599 & $98.51 \%$ \\
\hline & I disagree & 9 & $1.49 \%$ \\
\hline \multirow{2}{*}{$\begin{array}{l}\text { Mother should go for antenatal booking } \\
\text { before the third month of pregnancy } \\
n=608\end{array}$} & I agree & 474 & $77.96 \%$ \\
\hline & I disagree & 134 & $22.04 \%$ \\
\hline \multirow{2}{*}{$\begin{array}{l}\text { Antenatal follow up is good to monitor } \\
\text { mother's and fetus' health } n=608\end{array}$} & I agree & 605 & $99.51 \%$ \\
\hline & I disagree & 3 & $0.49 \%$ \\
\hline
\end{tabular}

weeks $[\mathrm{OR}=4.146$ 95\% CI 5.806, 21.398] were also more likely to book ANC within the recommended time compared to corresponding counterparts and these factors were found positively associated (Table 4).

\section{Discussion}

In this study, only about $21.72 \%$ of respondents have started their ANC within the recommended time with 95\% CI (18\%, $25 \%$ ) and the remaining $78.28 \%$ booked it lately with $95 \%$ CI $(75 \%, 81 \%)$. The timing of first booking ranged from first month after last menstrual period to ninth month of gestation. The proportion of women who came for their first ANC within recommended time is lower than studies done in Gondar, Addis Ababa, and higher than studies conducted in Hadiya, Kembata zone, Yem special district, and EDHS 2011 $[4,13,18-21]$. Possible explanation for this might be those who have more proportion of early ANC due to better access and awareness regarding services while the lower proportion may be due to time variation in this study and the access and awareness improvement.

According to the result, mothers of age $\leq 25$ years were found to be more likely to have early initiation of ANC when compared with others $(\mathrm{COR}=1.30995 \%$ CI 0.92, 2.458), but not significant. This idea was slightly supported by study done in Addis Ababa, Yem, Gondar, and Debrebrhan; this idea contradicts the study done in Tanzania (18-21, 8). This might be because younger mothers were more informed and convincible to seek appropriate prenatal care.

Respondents who had media access TV/radio initiated ANC within recommended time twice more likely when compared to those who had not $(\mathrm{AOR}=2.10995 \% \mathrm{CI}$ $1.001,4.445)$. This might be due to exposure to source of information, as result of the study indicated that prim gravid mothers start ANC timely 1.4 times more likely when compared to multigravid mothers $(\mathrm{AOR}=1.03895 \% \mathrm{CI}$ $1.02,1.92)$. Another study conducted in Tanzania showed that higher gravidity is more likely to be predictor of late antenatal care initiation compared to early ANC initiation [8]. This could be because prim gravid mothers may be younger and educated and easily understand an advice to commence ANC early and different information.

Parity of respondents was found to be more likely predictor of timely booking of ANC (COR = 1.429 95\% CI 0.951, 2.145), but not significant, and this finding was similar to that of study done in Debrebrhan and lower than the studies done in Gondar and Kembata Tembaro zone as parity was found as the most predictor for late utilization of ANC. The same studies revealed that pervious ANC utilization was also found to be a positive predictor for timely ANC booking [21, 22].

Perception of respondents concerning correct time of early initiation of ANC was highly associated with early initiation of ANC at recommended time and mothers who perceived right time to be in the first 12 weeks of gestation were nearly 4.5 times more likely to commence ANC timely than those who perceived right time beyond 12 weeks of gestation $(\mathrm{AOR}=4.49995 \% \mathrm{CI} 2.470,6.160)(P$ value $=$ $0.000)$. This finding was supported by and higher than other findings of many studies conducted in different parts of our country $[4,14,18,20]$.

The finding of this study revealed that the maternal perception concerning the correct time to ANC booking was similar to that of study done in Gondar town. This in fact may be determinant factor for early ANC initiation at recommended time [22].

The result of the study indicates that respondents who received correct advice to book ANC during recommended time after amenorrhea used early ANC 4 times more likely than those not advised about correct time (AOR $=4.14695 \%$ CI $3.806,21.398)(P$ value $=0.001)$. The study conducted 
TABLE 4: Association of factors with timely booking of first ANC, Shebedino district in 2015.

\begin{tabular}{|c|c|c|c|c|}
\hline \multirow{2}{*}{ Variables } & \multicolumn{2}{|c|}{ Time at first ANC visit } & \multirow{2}{*}{ Crude OR [CI] } & \multirow{2}{*}{ Adjusted OR $[\mathrm{CI}]$} \\
\hline & Booked early & Booked late & & \\
\hline \multicolumn{5}{|l|}{ Age of mother } \\
\hline Age $\geq 25$ & $61[19.48 \%]$ & $252[80.52 \%]$ & 1.00 & 1.00 \\
\hline Age $<25$ & $71[24.06 \%]$ & $224[75.94 \%]$ & $1.390[0.93,2.46]$ & $0.88[0.36,2.15]$ \\
\hline \multicolumn{5}{|l|}{ Place of residence } \\
\hline Urban & $13[20.63 \%]$ & $50[79.36 \%]$ & $0.93[0.56,2.04]$ & $0.57[0.20,1.61]$ \\
\hline Rural & 119 [21.71\%] & $426[78.29 \%]$ & 1.00 & 1.00 \\
\hline \multicolumn{5}{|l|}{ Media access } \\
\hline Had radio/TV & $81[26.04 \%]$ & $230[73.96 \%]$ & $1.69[1.02,2.20]$ & $2.11[1.00,4.44]^{* *}$ \\
\hline Had no radio/TV & $51[17.17 \%]$ & $246[82.83 \%]$ & 1.00 & 1.00 \\
\hline \multicolumn{5}{|l|}{ Educational level of mother } \\
\hline Primary and below & $109[23.42 \%]$ & $399[76.58 \%]$ & 1.00 & 1.00 \\
\hline Secondary and above & $23[23.00 \%]$ & $77[77.00 \%]$ & $1.08[0.63,1.53]$ & $1.64[0.55,4.89]$ \\
\hline \multicolumn{5}{|l|}{ Educational level of husband } \\
\hline Primary and below & $98[22.95 \%]$ & $329[77.05 \%]$ & 1.00 & 1.00 \\
\hline Secondary and above & $34[18.78 \%]$ & $147[81.22 \%]$ & $0.78[0.49,1.11]$ & $0.41[0.17,1.00]$ \\
\hline \multicolumn{5}{|l|}{ Occupation of mother } \\
\hline Employed & $10[21.27 \%]$ & $37[78.73 \%]$ & $0.97[0.47,1.47]$ & $0.62[0.18,1.19]$ \\
\hline Unemployed & $122[21.74 \%]$ & $439[78.26 \%]$ & 1.00 & 1.00 \\
\hline \multicolumn{5}{|l|}{ Gravity } \\
\hline Prim gravid & $48[28.23 \%]$ & $122[71.77 \%]$ & $1.65[1.10,2.19]$ & $1.04[1.02,1.72]^{* *}$ \\
\hline Two and above & 84 [19.19\%] & 354 [80.81\%] & 1.00 & 1.00 \\
\hline \multicolumn{5}{|l|}{ Parity of mother } \\
\hline No parity & 48 [18.32\%] & $214[81.68 \%]$ & 1.00 & 1.00 \\
\hline Parity one and above & $84[24.27 \%]$ & $262[75.73 \%]$ & $1.42[0.95,1.89]$ & $0.14[0.006,3.46]$ \\
\hline \multicolumn{5}{|l|}{ Perception on time of ANC initiation } \\
\hline Perceived at and before 12 weeks & $102[53.96 \%]$ & $87[46.04 \%]$ & $20.14[12.81,27.47]$ & $4.49[2.47,6.16]^{* * *}$ \\
\hline Perceived after 12 weeks & $22[5.50 \%]$ & $378[94.50 \%]$ & 1.00 & 1.00 \\
\hline \multicolumn{5}{|l|}{ Plan of pregnancy by mother } \\
\hline Planned & $102[21.29 \%]$ & $377[78.71 \%]$ & $0.89[0.70,1.08]$ & $0.72[0.26,1.34]$ \\
\hline Unplanned & $30[23.25 \%]$ & $99[76.75 \%]$ & 1.00 & 1.00 \\
\hline \multicolumn{5}{|l|}{ Plan of pregnancy by husband } \\
\hline Planned & $109[21.00 \%]$ & $410[79.00 \%]$ & $0.76[0.45,1.07]$ & $0.30[0.09,0.54]^{* *}$ \\
\hline Unplanned & $23[25.84 \%]$ & $66[74.16 \%]$ & 1.00 & 1.00 \\
\hline \multicolumn{5}{|l|}{ Advised when to start first ANC } \\
\hline $\begin{array}{l}\text { Advised to book before and at } 3 \\
\text { months of gestation }\end{array}$ & $93[55.35 \%]$ & $75[44.65 \%]$ & $17.80[11.21,24.39]$ & $4.14[3.80,6.21]^{* * *}$ \\
\hline $\begin{array}{l}\text { Advised to book after } 3 \text { months of } \\
\text { gestation }\end{array}$ & $19[6.52 \%]$ & $272[93.48 \%]$ & 1.00 & 1.00 \\
\hline \multicolumn{5}{|l|}{ Past experience of timing } \\
\hline $\begin{array}{l}\text { Book before and at } 3 \text { months of } \\
\text { gestation }\end{array}$ & $55[31.97 \%]$ & 117 [68.03\%] & $1.65[1.10,2.20]$ & $2.50[1.81,3.45]^{* * *}$ \\
\hline Book after 3 months of gestation & 19 [8.52\%] & $204[91.48 \%]$ & 1.00 & 1.00 \\
\hline
\end{tabular}

Note. Significant at ${ }^{* *} P \leq 0.05$ and ${ }^{* * *} P \leq 0.001$.

at Addis Ababa also concluded that physical and financial accessibility alone cannot assure effective service utilization of ANC. The need for proper advice and information on timely booking from service providers and community level and/or health institution is very important for the effective utilization of the service [16]. The current finding was also similar to that finding.

As revealed on the result of the study, occupation of the respondents had no effect on the early ANC initiation; this finding contradicts the study done in Kembata Tembaro 
[21]. And others like educational level of mothers and their husbands, parity, and pregnancy plan by mothers and their husbands were not statistically significant findings.

\section{Conclusion}

Early time of initiation for ANC at recommended time is low. Perception of mothers on correct time of ANC initiation, advice on correct time of ANC initiation, past experience of early booking of ANC, and media access are the positive predictors or factors of early ANC initiation. Multigravid mothers start ANC more early than prim gravid mothers. Health professionals and care providers should provide full information and advice and appropriate care about early ANC for every eligible mother. Mass media worker should include early initiation of ANC. Care takers should consider the importance of past experience of early ANC and perceive appropriate time to start ANC.

\section{Conflicts of Interest}

The authors declare that they have no conflicts of interest.

\section{Acknowledgments}

The authors would like to thank their family, respondents, data collectors, and supervisors.

\section{References}

[1] A. M. Rosliza and H. J. Muhamad, "Knowledge, attitude and practice on ANC among orang asil women in JEMPOL, NEGERI SEMBILAN," Malaysian Journal of Public Health Medicine, vol. 11, no. 2, pp. 13-21, 2011.

[2] Population, Reproductive Health and the Global Effort to End Poverty, 2014.

[3] S. Babalola and A. Fatusi, "Determinants of use of maternal health services in Nigeria-looking beyond individual and household factors," BMC Pregnancy and Childbirth, vol. 9, article 43, 2009.

[4] Ethiopia Demographic and Health Survey, 2011.

[5] CSA, Ethiopia Demographic and Health Survey 2015, Central Statistical Agency (CSA), Addis Ababa, Ethiopia; ICF Macro, Calverton, Md, USA, 2016.

[6] CSA, Ethiopia Demographic and Health Survey 2005, Central Statistical Agency (CSA), Addis Ababa, Ethiopia; ICF Macro, Calverton, Md, USA, 2006.

[7] CSA, Ethiopia Demographic and Health Survey 2000, Central Statistical Agency (CSA), Addis Ababa, Ethiopia; ORC Macro; ICF Macro, Calverton, Md, USA, 2001.

[8] R. Carine and J. G. Wendy, "Maternal mortality: who, when, where, and why," The Lancet, vol. 368, no. 9542, pp. 1189-1200, 2006.

[9] WHO, Make Every Mother and Child Count, WHO, Geneva, Switzerland, 2005.

[10] B. Simkhada, E. R. Van Teijlingen, M. Porter, and P. Simkhada, "Factors affecting the utilization of antenatal care in developing countries: systematic review of the literature," Journal of Advanced Nursing, vol. 61, no. 3, pp. 244-260, 2008.
[11] I. Banda, C. Michelo, and A. Hazemba, "Factors associated with late antenatal care attendance in selected rural and urban communities of the copperbelt province of Zambia," Medical Journal of Zambia, vol. 39, no. 3, pp. 29-36, 2012.

[12] Centers for Disease Control and Prevention, "Revised recommendations for HIV screening of pregnant women," MMWR Recommendations and Reports, vol. 50, pp. 63-85, quiz CE1-19a2-CE6-19a2, 2001.

[13] W. Delva, E. Yard, S. Luchters et al., "A Safe Motherhood project in Kenya: assessment of antenatal attendance, service provision and implications for PMTCT," Tropical Medicine \& International Health, vol. 15, no. 5, pp. 584-591, 2010.

[14] M. King, R. Mhlanga, and H. De Pinho, The Context of Maternal and Child Health, South African Health Review Health Systems Trust, Durban, South Africa, 2006.

[15] Z. Abosse, M. Woldie, and S. Ololo, "Factors influencing antenatal care service utilization in Hadiya zone," Ethiopian Journal of Health Sciences, vol. 20, no. 2, p. 78, 2010.

[16] TJ A, Why pregnant women delay to attend Prenatal care?, June 2008.

[17] W. Wang, S. Alva, S. Wang, and A. Fort, "Levels and trends in the use of maternal health services in developing countries," DHS Comparative Reports, ICF Macro, Calverton, Md, USA, 2011.

[18] K. T. Barnhart, B. Casanova, M. D. Sammel, K. Timbers, K. Chung, and J. L. Kulp, "Prediction of location of a symptomatic early gestation based solely on clinical presentation," Obstetrics and Gynecology, vol. 112, no. 6, pp. 1319-1326, 2008.

[19] T. W. Gudayu, S. M. Woldeyohannes, and A. A. Abdo, “Timing and factors associated with first antenatal care booking among pregnant mothers in Gondar Town; North West Ethiopia," BMC Pregnancy and Childbirth, vol. 14, article 287, 2014.

[20] T. Belayneh, M. Adefris, and G. Andargie, "Previous early antenatal service utilization improves timely booking: crosssectional study at University of Gondar Hospital, Northwest Ethiopia," Journal of Pregnancy, vol. 2014, Article ID 132494, 7 pages, 2014.

[21] T. Tekelab and B. Berhanu, "Factors associated with late initiation of antenatal care among pregnant women attending antenatal clinic at public health centers in Kembata Tembaro zone, Southern Ethiopia," Science, Technology and Arts Research Journal, vol. 3, no. 1, pp. 108-115, 2014.

[22] D. Nigatu, A. Gebremariam, M. Abera, T. Setegn, and K. Deribe, "Factors associated with women's autonomy regarding maternal and child health care utilization in Bale zone: a community based cross-sectional study," BMC Women's Health, vol. 14, no. 1, article 79, 2014.

[23] A. Exavery, A. M. Kanté, A. Hingora, G. Mbaruku, S. Pemba, and J. F. Phillips, "How mistimed and unwanted pregnancies affect timing of antenatal care initiation in three districts in Tanzania," BMC Pregnancy and Childbirth, vol. 13, article 35, 2013. 


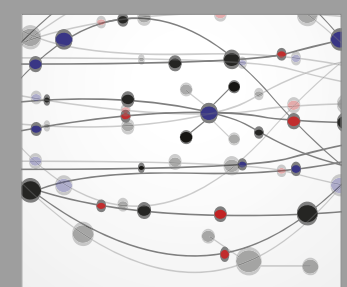

The Scientific World Journal
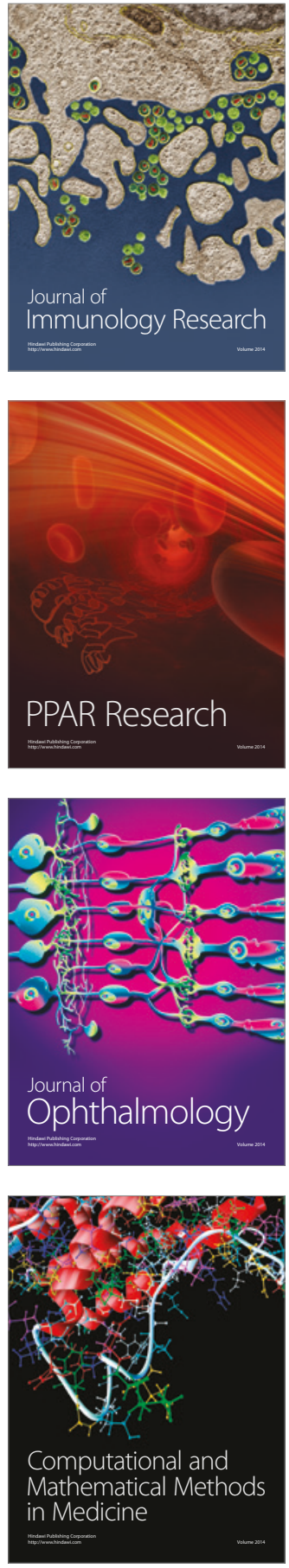

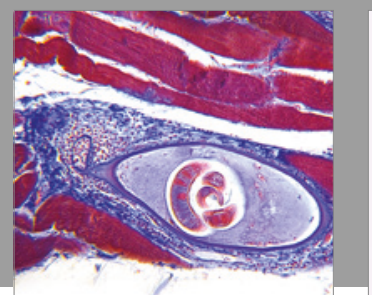

Gastroenterology Research and Practice
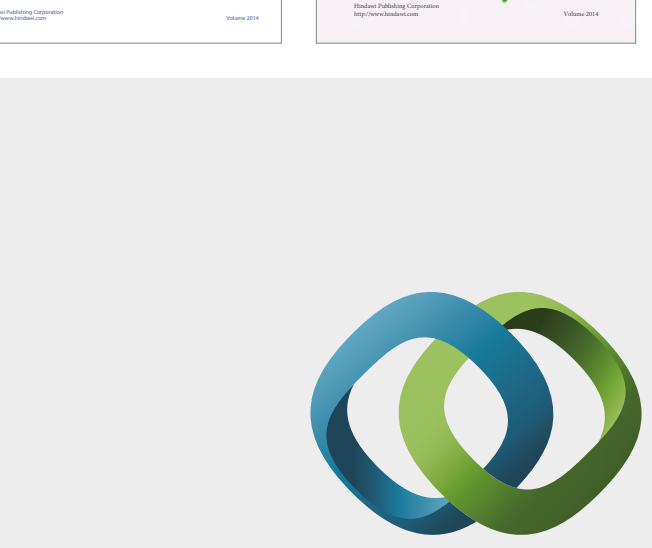

\section{Hindawi}

Submit your manuscripts at

https://www.hindawi.com
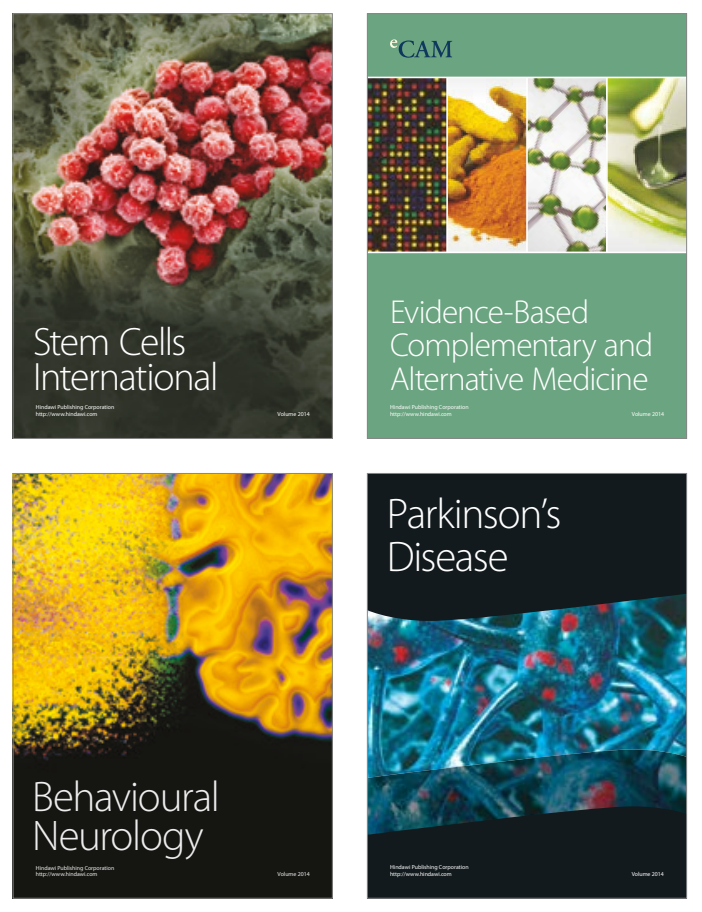
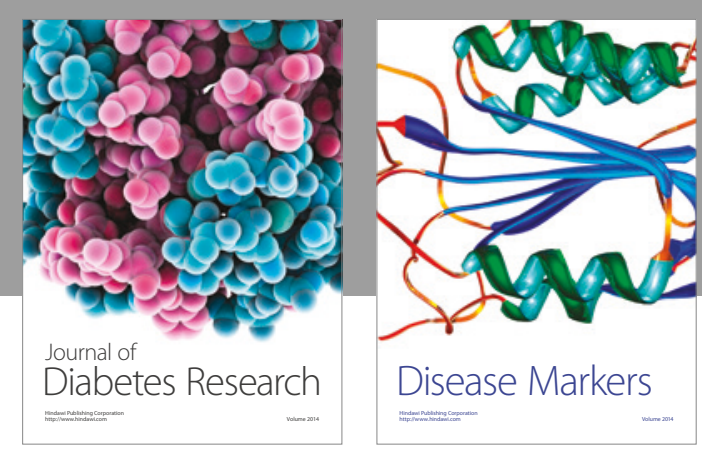

Disease Markers
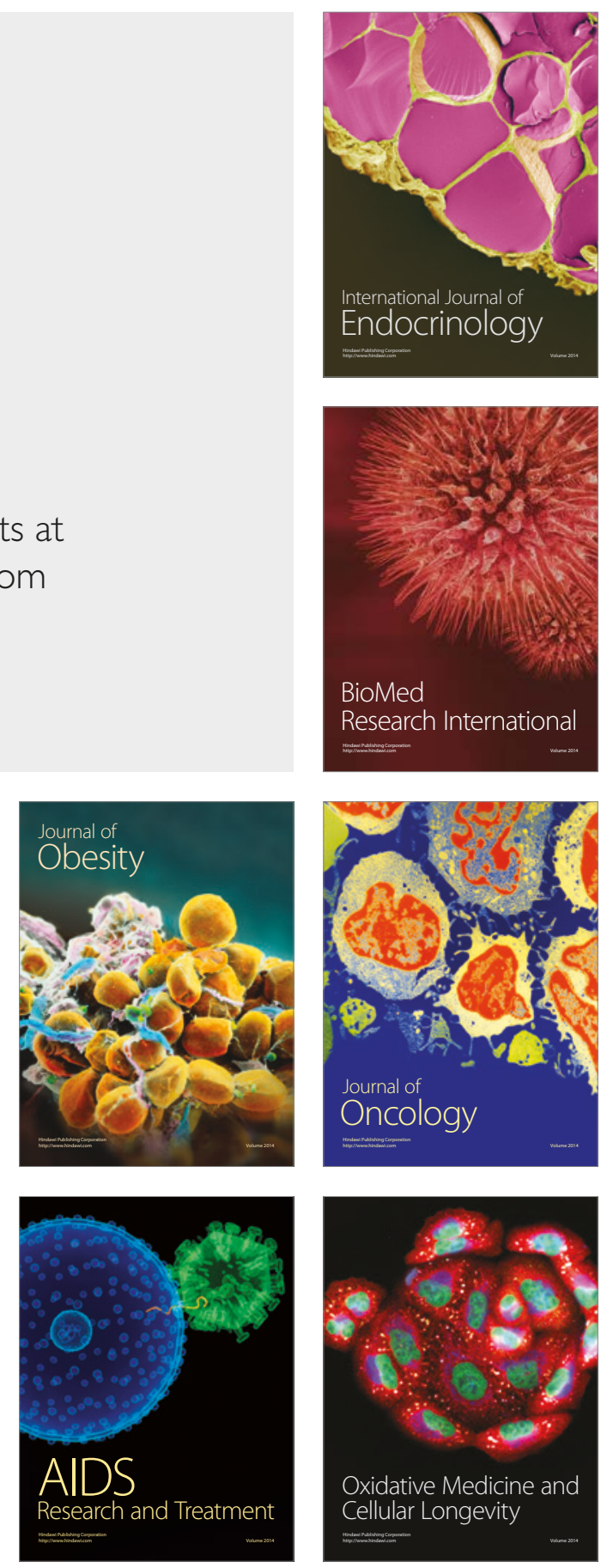